\title{
Formulation and characterization of EGCG for the treatment of superficial bladder cancer
}

\author{
KATARZYNA DETTLAFF ${ }^{1}$, MACIEJ STAWNY ${ }^{1}$, MAGDALENA OGRODOWCZYK ${ }^{1}$, ANNA JELIŃSKA ${ }^{1}$, \\ WALDEMAR BEDNARSKI ${ }^{2}$, DOROTA WĄTRÓBSKA-ŚSIETLIKOWSKA ${ }^{3}$, RICK W. KECK ${ }^{4}$, \\ OMAR A. KHAN ${ }^{4}$, IBRAHIM H. MOSTAFA ${ }^{4}$ and JERZY JANKUN ${ }^{4}$ \\ ${ }^{1}$ Department of Pharmaceutical Chemistry, Poznań University of Medical Sciences, 60-780 Poznań; \\ ${ }^{2}$ Institute of Molecular Physics, Polish Academy of Sciences, 60-179 Poznań; ${ }^{3}$ Department of Pharmaceutical Technology, \\ Medical University of Gdańsk, 80-416 Gdańsk, Poland; " Urology Research Center, Department of Urology, \\ College of Medicine, University of Toledo, Toledo, $\mathrm{OH} 43614$, USA
}

Received February 21, 2017; Accepted May 30, 2017

DOI: $10.3892 /$ ijmm.2017.3024

\begin{abstract}
In the United States, the annual incidence of bladder cancer is approximately 70,000 new cases, with a mortality rate of approximately 15,000 /year. The most common subtype (70\%) of bladder cancer is superficial, namely hte non-muscle invasive disease form limited to the urothelium. The rate of progression and recurrence is up to 40 and $70 \%$, respectively. Urothelial cell carcinoma of the bladder is typically treated with transurethral resection. The cancerous cells can float onto the adjacent epithelium, increasing the risk of recurrence. The standard of care is to offer adjuvant intravesical agents to reduce the risk of progression and recurrence. Current intravesical treatments are costly and are associated with special biohazard handling protocols. Patients are treated with intravesical therapy with bacillus Calmetter-Guerin (BCG) bacterium, or mitomycin C (MMC) following resection, both of which can cause moderate to severe side-effects which are rarely life-threatening. We previously examined the efficacy of epigallocatechin-3-gallate (EGCG) in comparison with MMC to prevent tumor cell implantation/growth in an animal model of superficial bladder cancer. Experiments revile that EGCG is slightly more effective than MMC at decreasing tumor cell implantation and consequent cancer growth in a bladder. This treatment requires the stringent sterile requirement of EGCG. EGCG can be unstable when sterilized at high temperatures. Thus, we evaluated two low temperature sterilization methods, such as ionizing radiation or the filtration method followed by freeze-drying. Both methods ensure the sterility of the sample; however, infrared and HPLC analysis revealed a slightly better stability of irradiated EGCG over the filtration method. The concentration of stable free radi-
\end{abstract}

Correspondence to: Professor Jerzy Jankun, Urology Research Center, Department of Urology, College of Medicine, University of Toledo, 3000 Arlington Avenue, Toledo, OH 43614, USA

E-mail: jerzy.jankun@utoledo.edu

Key words: superficial bladder cancer, epigallocatechin-3-gallate, formulation cals following irradiation was low, which are unlikely to exert any damaging effects to EGCG. Therefore, we consider that radiation will be the preferred method of EGCG sterilization, and that this may prove useful for the effective use of EGCG in the treatment of bladder cancer.

\section{Introduction}

In the United States, the incidence of urothelial cell carcinoma (UCC) of the bladder or transitional cell carcinoma (TCC) is approximately 70,000 new cases annually, leading to approximately 15,000 deaths. The risk factors for TCC are many, but most commonly include smoking, chronic cystitis and chemical exposure, including exposure to aniline dye. Initial presentation most commonly appears in the form of gross hematuria, but can also present with irritative voiding symptoms, anemia and renal failure due to obstruction. The most common subtype of bladder cancer is superficial bladder cancer, namely the nonmuscle invasive form limited to the urothelium. Of all new cases of bladder cancer, the non-muscle invasive type accounts for nearly $70 \%$. The rate of progression and recurrence is up to 40 and $70 \%$, respectively $(1,2)$.

The gold standard initial treatment for bladder cancer includes cystoscopy and transurethral resection of the bladder tumor. During this time, malignant cells can float onto the adjacent epithelium, increasing the risk of recurrence. Once pathological evaluation confirms a non-muscle invasive disease, the standard of care to prevent recurrence and progression is the intravesical instillation of immunotherapeutic agents. Intravesical immunotherapy results in a massive local immune response characterized by the induced expression of cytokines in the urine and bladder wall and by an influx of granulocytes, and mononuclear and dendritic cells $(3,4)$. Current intravesical treatments are costly and require the special handling of these agents. Patients are treated with intravesical therapy with bacillus Calmette-Guerin (BCG) bacterium, or mitomycin $\mathrm{C}$ (MMC) following resection. Both of these can cause severe side-effects, which are rarely life-threatening (3).

$\mathrm{BCG}$, is an attenuated live vaccine for tuberculosis that has shown antitumor activity. The proposed mechanism of action 
is T-cell activation to attack abnormal urothelial cells and this may have a direct inhibitory effect on tumor cell invasion. Intravesical BCG has been shown to decrease tumor recurrence and progression. Intravesical treatment usually begins 2-4 weeks following transurethral resection to minimize systemic absorption and undesirable side-effects. Treatment regimens include an induction phase that consists of weekly instillation for 6 weeks as long as the patient can tolerate the agent. This is followed by a maintenance regimen that can last for 1-3 years, depending on the tumor grade and characteristics. Side-effects of the agent include cystitis, dysuria, malaise, fatigue and systemic inflammatory response syndrome, and can be as severe as BCG sepsis. Contraindications include immunosuppression, traumatic catheterization, active urinary tract infection or gross hematuria and a personal history of BCG sepsis (3,5-8). MMC is an alkylating agent that inhibits DNA synthesis. Intravesical MMC has a clear impact on tumor recurrence when immediately instilled following the transurethral resection of bladder tumor and in the adjuvant setting. There is no clear evidence of an impact on progression. MMC is usually administered immediately following the resection of the bladder tumor, as long as bladder perforation has not occurred. Systemic absorption, which can cause myelosuppression, is rare as MMC has a high molecular weight. Common side-effects include contact dermatitis and irritative voiding symptoms $(3,5-8)$.

A meta-analysis of 9 clinical trials compared its efficacy on progression with that of BCG. Within a median follow-up of 26 months, $7.67 \%$ of the patients in the BCG group and $9.44 \%$ of the patients in the MMC group developed tumor progression (9). Another review found a $38 \%$ reduction in tumor recurrence with MMC. This was not as effective as BCG, but was considered in most studies to make MMC a viable option in light of its lesser side-effects, particularly the low, but real risk of sepsis (10).

We previously examined the efficacy of epigallocatechin-3-gallate (EGCG) in comparison with MMC in the prevention of tumor cell implantation/growth in an animal model of superficial bladder cancer (11). EGCG $\{[(2 R, 3 R)-5,7$-dihydroxy-2-(3,4,5-trihydroxyphenyl)chroman-

3-yl] 3,4,5-trihydroxybenzoate; Fig. 1\} is the most abundant catechin in green tea. EGCG and green tea extracts are under investigation for their potential effects on human health and disease (12-15). One of the promising uses of EGCG and green tea extracts is the prevention and treatment of cancer (16-19). Experiments on cells in vitro and on animal models in vivo have shown the anti-neoplastic activity of EGCG (17,20-24). However, the mechanism of action of EGCG is poorly understood due to the deficiency of analytical tools that can detect the precise behavior of such a small molecule. Nevertheless, numerous possible targets have been suggested, such as Janus kinase (JAK)/signal transducer and activator of transcription (STAT), mitogen-activated protein kinase (MAPK), phosphoinositide 3-kinase (PI3K)/AKT (25), urokinase-type plasminogen activator (UPA) and matrix metalloproteinases (MMPs) (26-29). The mechanisms of action of EGCG make matters more complicated, given the fact that it is labile in aqueous solutions. It has been reported that auto-oxidation and epimerization are the two major reactions responsible for the instability of EGCG (30). Green tea catechins, including
EGCG bind to plasma proteins that alter their plasma concentration, tissue delivery and biological activity. Incubation with human serum albumin (HSA) green tea extracts and pure EGCG results in full binding to HSA $(31,32)$. Moreover, poor absorption results in the low systemic bioavailability of EGCG following oral administration and its conversion to the glucuronide renders EGCG even less available in the circulation (33,34). EGCG is highly unstable under sunlight (35). This polyphenol, following exposure to irradiance, such as natural sunlight, photo-degrades approximately 69\%, after $1 \mathrm{~h}$ of irradiation. The inclusion of UVB $(290-320 \mathrm{~nm})$ produces a photo-degradation EGCG of $61 \%$ (36). However, at least to the best of our knowledge, there are no studies available to date on the effects of ionizing radiation on the stability of this polyphenol. Therefore, it seems that it is safer to use green tea extracts or EGCG in situ for the treatment of different ailments. There are several clinical studies on humans using topical EGCG treatment (37-39). EGCG treatment has also been approved by the United States Food and Drug Administration (polyphenon E - purified extract of green tea) ointment for external genital warts treatment $(40,41)$.

We previously studied the efficacy of EGCG in comparison with MMC to prevent tumor cell implantation/growth in an animal model of superficial bladder cancer and investigated the possible mechanisms of action. Female Fisher 344 rats were used to study the in situ effects of EGCG and MMC for the prevention of transitional rat cell tumor implantation (AY-27) (11). Experiments revile the slightly better effects of EGCG than MMC in these experimental animals. Thus, EGCG can be used as an agent to decrease tumor cell implantation and consequent intravesical cancer growth in a bladder. The use of EGCG is a potential novel therapeutic strategy for use as an adjunct to endoscopic bladder tumor resection. These data suggest that EGCG lowers proteolytic activity and decreases the probability of cancer cell implantation rather than direct cancer cell cytotoxicity. Molecular modeling suggests that EGCG inhibits uPA and matrix MMP-9 $(11,42,43)$. In preparation for clinical studies, in this study, we wished to determine the stability of EGCG during different sterilization processes for use in the treatment of superficial transitional cell carcinoma of the human bladder.

\section{Materials and methods}

Chemicals. EGCG and Polyphenon $\mathrm{E}^{\circledR}$ (highly purified green tea extract) were generous gifts from Taiyo International Inc., Minneapolis, MN, USA.

Sterilization of EGCG by filtration and lyophilization. Under aseptic conditions, $1,100 \mathrm{mg}$ of EGCG were dissolved in $80.0 \mathrm{ml}$ distilled water and filtrated through a $0.2 \mu \mathrm{m}$ filter. The solution was aliquoted into 20 sterile vials dosing accurately $4.0 \mathrm{~g}$ of solution per one vial. The solution of EGCG $(4 \mathrm{ml})$ in the vials was freeze-dried using a vacuum freeze-dryer (Alpha type 2-4; Martin Christ, Harz, Germany) immediately after preparation. No lyoprotectant was added to the vials. The samples were frozen to a terminal temperature of $-45^{\circ} \mathrm{C}$ and were kept at this temperature for $5 \mathrm{~h}$. Primary drying was performed by keeping the vials for $43 \mathrm{~h}$ at a pressure of 1.03 mbar, during which the temperature of the freeze-dryer 
shelf slowly increased up to $0^{\circ} \mathrm{C}$. Secondary drying was carried out by reducing the pressure to $0.1 \mathrm{mbar}$ and increasing the shelf temperature to $30^{\circ} \mathrm{C}$. Secondary drying time was $7 \mathrm{~h}$. Lyophilization was terminated by venting the drying chamber with air.

Irradiation with e-beam. Approximately $0.5 \mathrm{~g}$ of EGCG was placed in $4 \mathrm{ml}$ colorless glass vials closed with a plastic stopper and irradiated 25, 100 and $200 \mathrm{kGy}$ with the e-beam from a linear electron accelerator Elektronika 10/10. The energy of electrons was set up for $9.96 \mathrm{MeV}$ and the current intensity of $6.2 \mu \mathrm{A}$.

Melting point determination. Melting temperature was determined using Meltter Toledo MP70 (Toledo, OH, USA) instrument in temperature $180-230^{\circ} \mathrm{C}$ increasing temperature $1^{\circ} \mathrm{C} / \mathrm{min}$.

Fourier transform infrared spectroscopy (FTIR). Samples of EGCG (1 mg each) irradiated with 25 and $200 \mathrm{kGy}$ dose, lyophilized, or the unirradiated control were mixed with $300 \mathrm{mg}$ of $\mathrm{KBr}$ to produce tablets $(1.3 \mathrm{~cm}$ x $0.1 \mathrm{~cm})$. FTIR spectrums were collected on an IRAffinity-1S Fourier Transform Infrared Spectrophotometer (Shimadzu, Kyoto, Japan) instrument in range of $400-4,000 \mathrm{~cm}^{-1}$, with a resolution of $4.0 \mathrm{~cm}^{-1}$ and 40 scans.

Ultraviolet $(U V)$-visible spectrophotometry. Samples of EGCG (1 mg each) irradiated with 25 and $200 \mathrm{kGy}$ dose, lyophilized, or the unirradiated control were dissolved in $0.9 \% \mathrm{NaCl}$ and diluted 1:25 in the same solution. Samples were analyzed using a PerkinElmer spectrophotometer (PerkinElmer, Inc., Waltham, MA, USA) in a $200-400 \mathrm{~nm}$ range.

High-performance liquid chromatography (HPLC). EGCG, irradiated EGCG and the lyophilized samples were analyzed by the HPLC method for the quantitative determination of the content. The HPLC equipment includes a Merck Hitachi L-7100 HPLC pump, a L-7450 photo diode array detector, a L-7200 autosampler, a D-700 interphase module and a column oven (Merck, Hitachi, England). The analytical column was reverse phase C18 (LiChrospher 100, endcapped $5 \mu \mathrm{m}$ ) 250x4 mm. The following solvents were used: $1 \%$ acetic acid - acetonitryle $75: 25(\mathrm{v} / \mathrm{v})$, flow $0.8 \mathrm{ml} / \mathrm{min}$. All solvents were filtered through a $0.45 \mu \mathrm{m}$ filter and degassed by ultrasonication. Separation was performed at $25^{\circ} \mathrm{C}$ and the analytical wavelength was set up for $280 \mathrm{~nm}$.

Electron paramagnetic resonance $(E P R)$ spectroscopy. Continuous-wave X-band $(9.4 \mathrm{GHz})$ electron paramagnetic resonance measurements were performed on a Bruker ELEXSYS E500 spectrometer with a ER49X SuperX microwave bridge equipped with super high sensitivity probehead (Bruker BioSpin GmbH, Rheinstetten, Germany). Magnetic field measurements were achieved by an NMT-Teslameter ER 036 ${ }^{\mathrm{TM}}$ (Bruker BioSpin GmbH). All EPR experiments were performed at room temperature. Spin concentration was obtained after double integration of EPR spectra according to the procedure described elsewhere (44). The number of free radicals was calculated from EPR spectra recorded at low microwave power $(0.5 \mathrm{~mW})$ to avoid saturation effects.<smiles>O=C(O[C@H]1Cc2c(O)cc(O)cc2O[C@H]1c1cc(O)c(O)c(O)c1)c1cc(O)c(O)c(O)c1</smiles>

Figure 1. Structure of epigallocatechin-3-gallate (EGCG).

Microbiological assay. The following reference strains were used: Pseudomonas aeruginosa ATCC 9027, Staphylococcus aureus ATCC 6538, Bacillus subtilis ATCC 6633, Clostridium sporogenes ATCC 19404, Candida albicans ATCC 10231, and Aspergillus brasiliensis ATCC 16404. The strains were obtained from the American Type Culture Collection (ATCC; Manassas, VA, USA). Culture media and solutions were as follows: soybean-casein digest medium and fluid thioglycollate medium (both from Merck Millipore, VWR International SAS, Fontenay-sous-Bois, France). Sterile sodium chloride, $9 \mathrm{~g} / 1$ solution was from Polpharma (Starogard, Poland). Growth promotion test of aerobes, anaerobes and fungi was done under aseptic condition. Portion of fluid thioglycollate medium was inoculated with $100 \mathrm{CFU}$ of the separate species of micro-organism: Clostridium sporogenes, Pseudomonas aeruginosa and Staphylococcus aureus. A portion of soyabean-casein digest medium was inoculated with Bacillus subtilis, Candida albicans and Aspergillus brasiliensis. All media were incubated for 3 days for bacteria and 5 days for fungi.

Cell proliferation assay. The AY-27 rat transitional cell line was a generous gift from Dr Samuel Cohen, Department of Pathology and Microbiology, University of Nebraska Medical Center and was grown in RPMI-1640 medium supplemented with $10 \%$ fetal bovine serum (FBS), penicillin and streptomycin. Cells $\left(10^{4}\right.$ cells/well) were treated with $100 \mu \mathrm{M}$ of control, irradiated (25 kGy) and lyophilized EGCG for $2 \mathrm{~h}$ after which fresh media replaced and cells were grown for $48 \mathrm{~h}$ (42). Cell proliferation assay was carried out using the CellTiter $96^{\circledR}$ Non-Radioactive Cell Proliferation Assay kit from Promega (Madison, WI, USA). The assay was carried out according to the manufacturer's instructions

\section{Results}

The research methodology and analytical methods were selected to show changes in chemical structure and a polymorphic form to demonstrate the presence of degradation products and free radicals in sterilized EGCG in comparison to the control samples. By comparing the spectra of FTIR-irradiated EGCG and control samples, we did not detect differences in the individual absorption bands or shifts in spectrums, showing that ionizing radiation at a dose of both 25 and $200 \mathrm{kGy}$ does not cause the production 

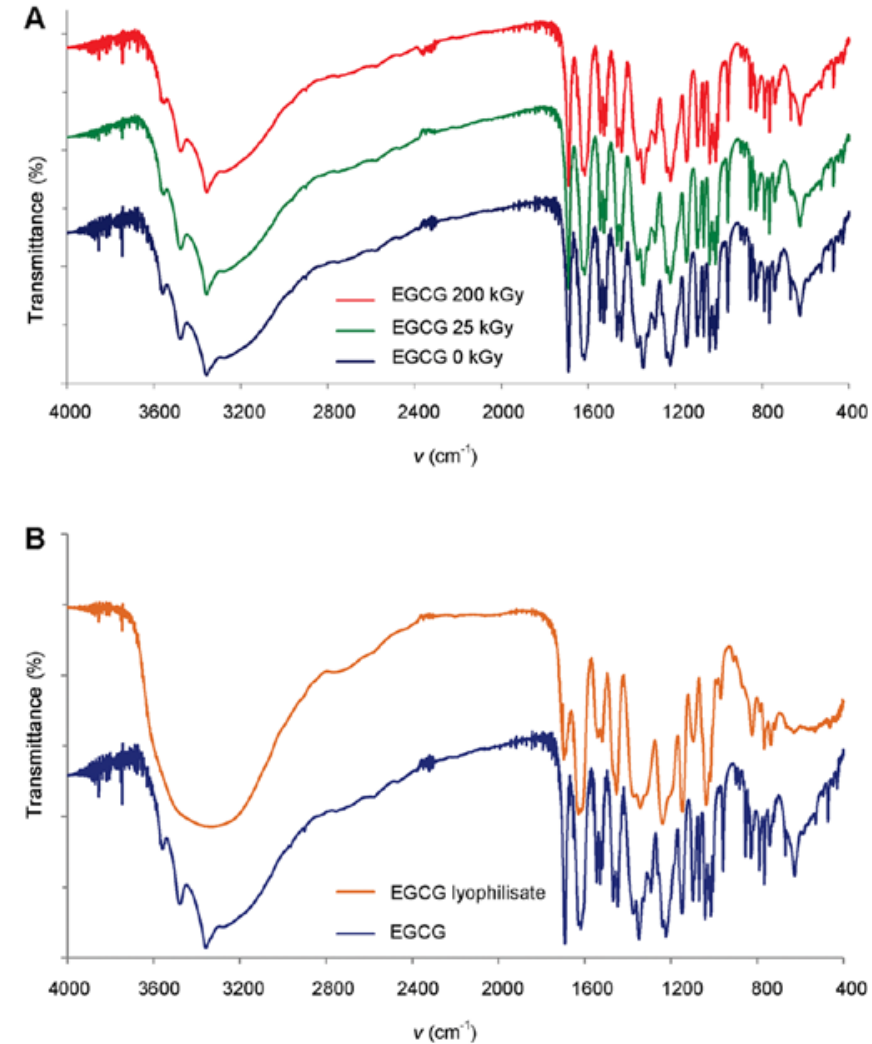

Figure 2. (A) Fourier transform infrared spectroscopy (FTIR) spectra of epigallocatechin-3-gallate (EGCG) before and after irradiation. (B) FTIR spectra of EGCG before and after filtration and lyophilization.

of degradation products detectable by FTIR, or changes the form of polymorphic forms (Fig. 2A). Different results were obtained for EGCG sterilized by filtration and freeze-dried. FTIR spectrums showed most dominant changes in the range of 3,600-3,200 $\mathrm{cm}^{-1}$ among some others (Fig. 2B), which may be the result of hydration of compound in the fingerprint region or changes of morphological form of this compound.

Changes in the form of EGCG can be monitored by the determination of the temperature of the melting point using the capillary method as well. The melting point analysis determines that EGCG does not show the properties of a typical crystalline compound. Samples of EGCG during heating change color from a light pink to dark pink followed by black products thermodegradation, and then finally the test substance is melted and completely degraded. The process was similar to the samples irradiated and not radiated at a dose of $25 \mathrm{kGy}$. However, EGCG samples irradiated with doses of 100 and $200 \mathrm{kGy}$ showed little reduction in the melting temperature $\left(1.0-1.3^{\circ} \mathrm{C}\right)$ (Table I). For a sample of EGCG sterilized by filtration and dried by lyophilization, we did not observe characteristic melting, which can be an indication of the completely amorphic form of this compound. Regardless of some changes in the polymorphic form of EGCG during radiation and specially the freeze drying process, aqueous solutions exhibit very similar spectrum in the range of 200-400 nm (Fig. 3).

HPLC analysis revealed that the control EGCG and EGCG irradiated with a dose of $25 \mathrm{kGy}$ was not altered (Fig. 4). Quantitative analysis of the results indicated that the content of EGCG following irradiation with a dose of $25 \mathrm{kGy}$ was

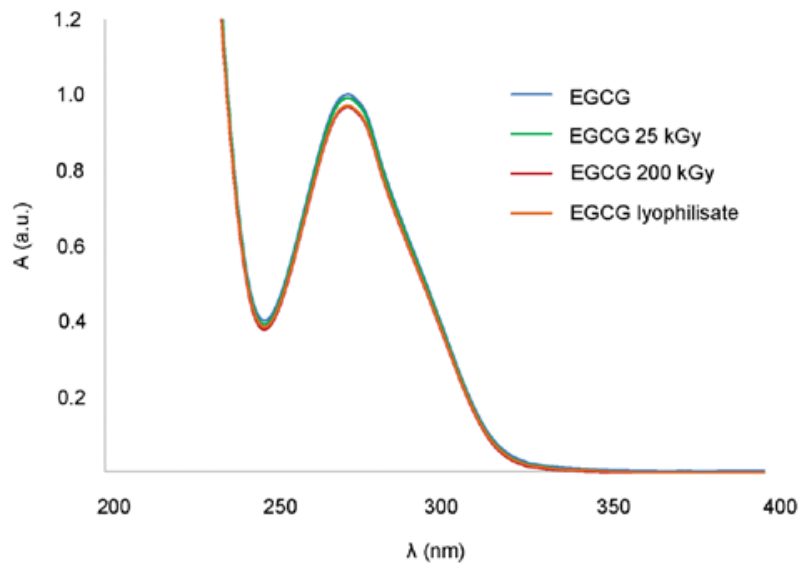

Figure 3. Ultraviolet (UV) spectra of epigallocatechin-3-gallate solutions before and after the sterilization processes.

Table I. Parameters of EGCG melting point before and after irradiation.

\begin{tabular}{rccc}
\hline $\begin{array}{l}\text { Dose } \\
(\mathrm{kGy})\end{array}$ & $\begin{array}{c}\text { Beginning of melting } \\
\text { process } \mathrm{T}_{\mathrm{b}}\left({ }^{\circ} \mathrm{C}\right)\end{array}$ & $\begin{array}{c}\text { End of melting } \\
\text { process } \mathrm{T}_{\mathrm{e}}\left({ }^{\circ} \mathrm{C}\right)\end{array}$ & $\begin{array}{c}\Delta \mathrm{T}_{\mathrm{e}}-\mathrm{T}_{\mathrm{b}} \\
\left({ }^{\circ} \mathrm{C}\right)\end{array}$ \\
\hline 0 & 202.2 & 206.2 & 4.0 \\
25 & 202.3 & 206.2 & 3.9 \\
100 & 201.2 & 204.0 & 3.8 \\
200 & 200.9 & 203.8 & 3.8 \\
\hline
\end{tabular}

EGCG, epigallocatechin-3-gallate.

changed by $0.5 \%$. With increasing doses of radiation, we further observed the loss of EGCG content (100 kGy of 1.4\% and $200 \mathrm{kGy}$ of $2.1 \%$ ), which is an indication that ionizing radiation causes some distraction of the tested compound. The chromatogram of lyophilized EGCG had additional peaks between 3 and 4 min of retention time, which are evidence of the presence of degradation products, which can also be a cause of changes in the FTIR spectra. Moreover, quantitative analysis of the results obtained indicated that the content of EGCG after the freeze-drying process decreased by $0.6 \%$ (data not shown).

EPR spectrum of unirradiated EGCG consists of a single free radical line $\mathrm{R}_{1}$ characterized by the spectroscopic coefficient $g=2.0040( \pm 0.0005)$ and line width $6( \pm 0.5)$ Gs (Fig. 5). The level of free radicals for this sample was time-independent (Fig. 6) and reached only 0.13 ppm (Table II). No hyperfine structure indicates that the unpaired electron is localized mainly on oxygen and free radicals are formed by the removal of one hydrogen atom from the $\mathrm{OH}$ group. An irradiation dose of $25 \mathrm{kGy}$ creates additional free radicals of which the concentration reaches $1.18 \mathrm{ppm}$. In addition to free radical $\mathrm{R}_{1}$, one can observe another radical $R_{2}$ (the same g-factor value as for $R_{1}$ ) with hyperfine structure derived from the three non-equivalent hydrogen nuclei. This radical is characterized by hyperfine constant: $\mathrm{A}_{\mathrm{H} 1}=44.5( \pm 1) \mathrm{Gs}, \mathrm{A}_{\mathrm{H} 2}=34.5( \pm 1) \mathrm{Gs}, \mathrm{A}_{\mathrm{H} 3}=10( \pm 1) \mathrm{Gs}$, and most probably is created by the removal of one hydrogen atom from the $\mathrm{CH}_{2}$ or $\mathrm{CH}$ group of chromene ring. The spectra of more irradiated EGCG (100 and $200 \mathrm{kGy}$ ) show additional 

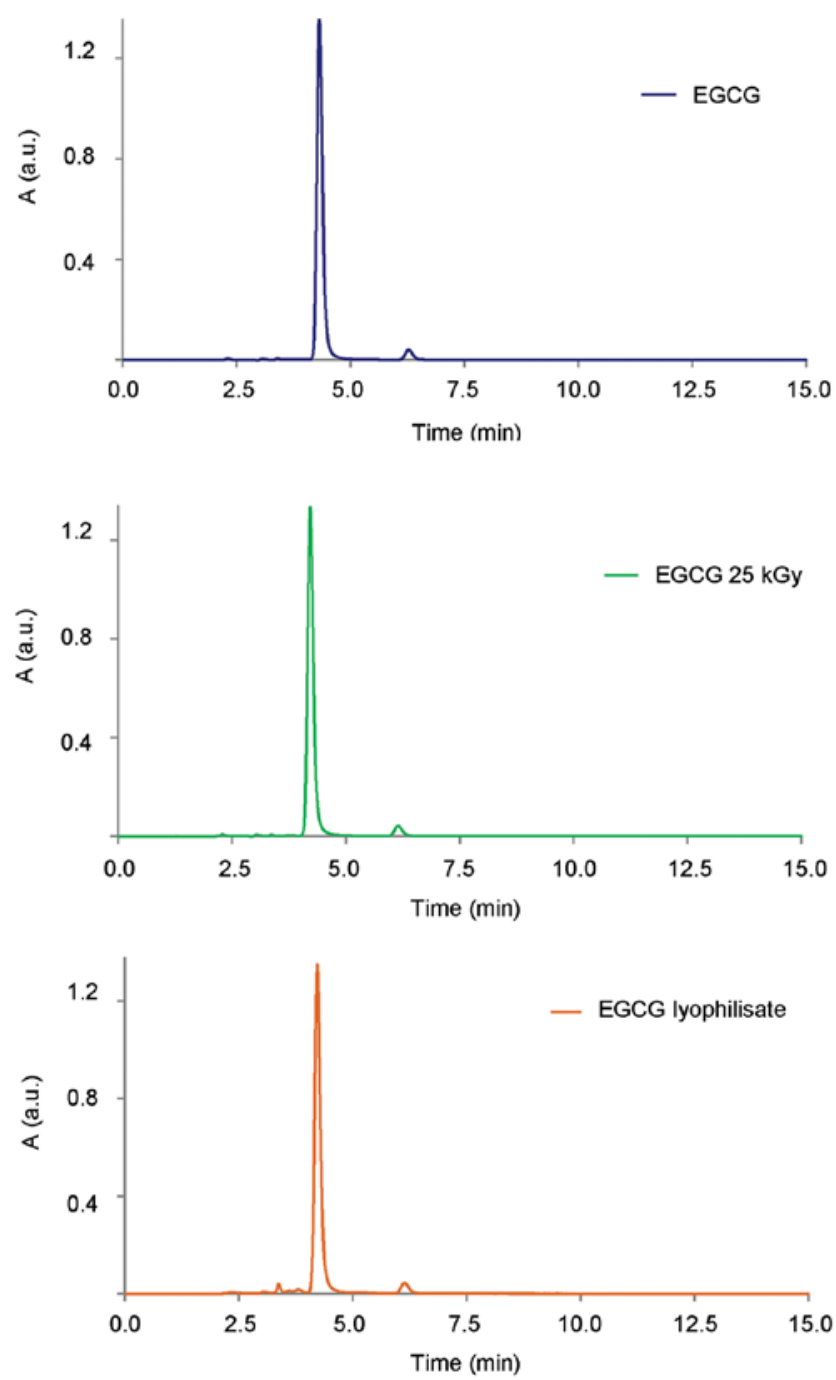

Figure 4. HPLC chromatograms of epigallocatechin-3-gallate (EGCG) before and after the sterilization processes.

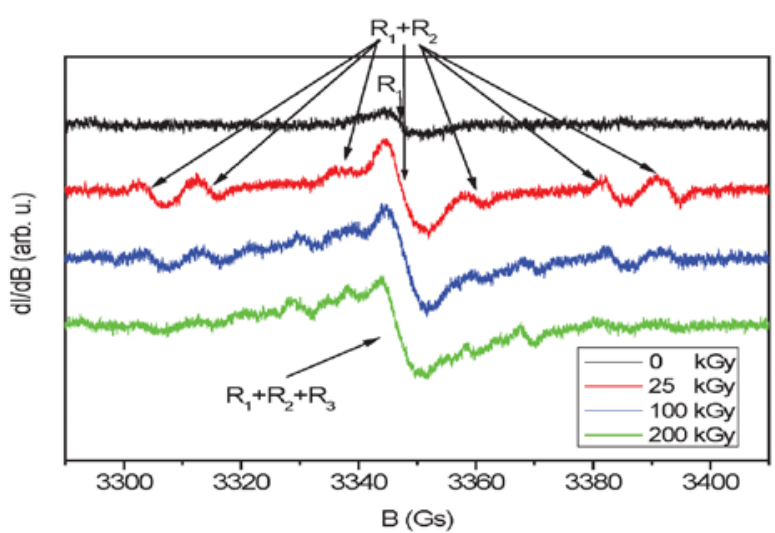

Figure 5. Electron paramagnetic resonance (EPR) spectra of unirradiated and irradiated epigallocatechin-3-gallate (EGCG) recorded $24 \mathrm{~h}$ after irradiation.

lines $\left(\mathrm{R}_{3}\right)$ coming from radicals produced as a result of subsequent hydrogen radiation defects. Time-dependent free radical concentration $\mathrm{C}(t)$ for sterilized samples (Fig. 6) can be described by the following equation:

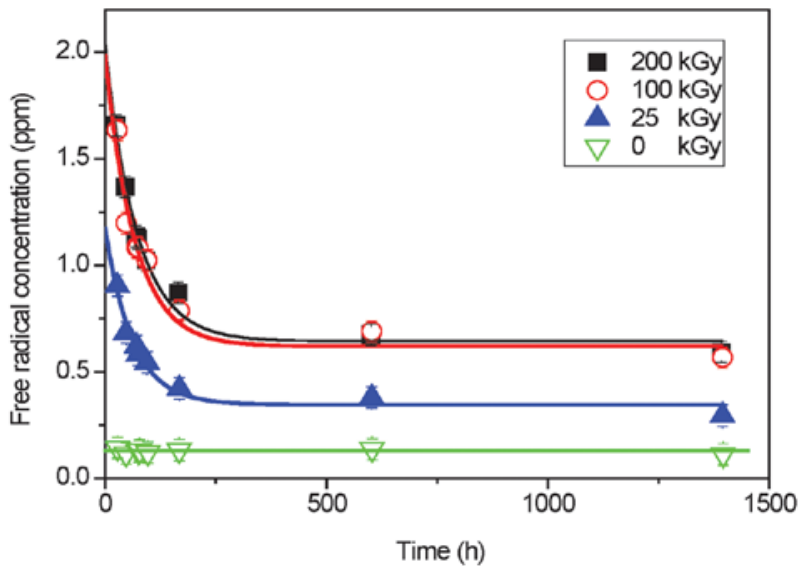

Figure 6. Free radical concentration for unirradiated and irradiated epigallocatechin-3-gallate (EGCG) vs. time, symbols - experimental points, lines - approximations according to equation 1.

$$
C(t)=C_{f}+C_{0} e^{\frac{-t}{T_{0}}}
$$

where $\mathrm{C}_{\mathrm{f}}$ is the concentration of stable free radicals, $\mathrm{C}_{0}$ is the concentration of unstable free radicals and $T_{0}$ is the mean lifetime of unstable free radicals, $t$ is time.

Although, as shown in Table II unstable free radicals are characterized by comparable values of the mean lifetimes for all sterilized drugs, one can notice that increasing dose of irradiation causes a slight increase in the mean lifetime. Moreover, the concentration of free radicals does not increase linear with a dose of irradiation (almost the same parameters in Table II for 100 and $200 \mathrm{kGy}$ ) suggesting additional creation of non-radical defects.

We did not observe any statistically significant changes in the growth characteristics of the cells treated with control EGCG, irradiated and lyophilized EGCG (data not shown).

\section{Discussion}

Local treatment of bladder cancer offers several benefits such us: (i) precise control of the amount of medication delivered to the bladder; (ii) high bioavailability with a low dose used; and (iii) the short time of treatment prevents the degradation or modification of the drug used. However, current intravesical treatments are extremely costly and require the special handling of these anti-neoplastic agents. Initially, superficial bladder cancer is treated with transurethral resection (TUR), during which cancer cells float freely onto the adjacent epithelium, potentially increasing the risk of recurrence (45-50). To prevent this scenario, patients are treated with intravesical therapy with BCG bacterium related to tuberculosis $(51,52)$, or MMC following resection or fulguration (destroying the lesion by electric current) or both agents (53). BCG, a form of immunotherapy, can cause side-effects, such as flu-like syndrome with fever, chills and fatigue, cystitis, or a more serious systemic reaction which rarely leads to death $(54,55)$. MMC is utilized similarly and carries its own drawbacks to clinical use, including bladder infection, irritative voiding symptoms, special handling and preparation precautions, and bladder calcifications among others (55-58).

We previously evaluated green tea extracts containing EGCG as a potential novel intravesical agent for the prevention 
Table II. Parameters describing the concentration of free radicals vs. time for no irradiated and irradiated EGCG.

\begin{tabular}{rccccc}
\hline Samples & $\begin{array}{c}\text { Initial concentration } \\
\text { of radicals at } \mathrm{t}=0 \\
\mathrm{C}(\mathrm{t}=0)=\mathrm{C}_{\mathrm{f}}+\mathrm{C}_{0}(\mathrm{ppm})\end{array}$ & $\begin{array}{c}\text { Concentration of } \\
\text { stable radicals } \\
\mathrm{C}_{\mathrm{f}}(\mathrm{ppm})\end{array}$ & $\begin{array}{c}\text { Concentration of } \\
\text { unstable radicals } \\
\text { at } \mathrm{t}=0 \mathrm{C}_{0}(\mathrm{ppm})\end{array}$ & $\begin{array}{c}\text { Mean lifetime of } \\
\text { unstable radicals } \\
\mathrm{T}_{0}(\mathrm{~h})\end{array}$ & $\begin{array}{c}\text { Half-life of } \\
\text { unstable radicals } \\
\mathrm{T}_{1 / 2}(\mathrm{~h})\end{array}$ \\
\hline $0 \mathrm{kGy}$ & $0.13 \pm 0.5$ & $0.13 \pm 0.5$ & - & - & - \\
$25 \mathrm{kGy}$ & $1.18 \pm 0.11$ & $0.35 \pm 0.02$ & $0.83 \pm 0.09$ & $61.8 \pm 10.4$ & $42.8 \pm 7.2$ \\
$100 \mathrm{kGy}$ & $1.98 \pm 0.26$ & $0.62 \pm 0.06$ & $1.36 \pm 0.20$ & $66.4 \pm 15.4$ & $46.0 \pm 10.6$ \\
$200 \mathrm{kGy}$ & $2.02 \pm 0.16$ & $0.64 \pm 0.04$ & $1.38 \pm 0.12$ & $71.6 \pm 10.0$ & $49.6 \pm 6.9$ \\
\hline
\end{tabular}

EGCG, epigallocatechin-3-gallate.

of cell tumor implantation. Preliminary experiments were very promising. EGCG treatment for 30-60 $\mathrm{min}$ in the bladder of experimental animals was equally or slightly superior to that of the commonly used MMC. Thus, EGCG inhibits uPA and MMP-9 enzymes, preventing cancer cell implantation and cancer recurrence (11).

EGCG and green tea extracts have been shown to exert many health-promoting effects, functioning through numerous pathways such as antioxidant and anti-inflammatory pathways, exhibiting gene expression activity, acting through growth factor pathways. However, the results of in vitro and in vivo experiments are frequently conflicting (59). This may be related to poor EGCG bioavailability, its oxidation that starts during contact with air, gastrointestinal inactivation, liver metabolism, or hard water $(27,59,60)$. The majority of clinical studies on human treatment with EGCG were carried out using the oral administration route $(33,61,62)$. This treatment does not require the stringent sterile requirement of EGCG; however, bladder installation following transurethral resection does.

The sterilization of EGCG can be challenging. For example, canned and bottled green tea beverages are widely popular worldwide, but preparation requires pasteurization by autoclaving at $120^{\circ} \mathrm{C}$ for several minutes. During this process, considerable amounts (approximately 50\%) of EGCG undergo epimerization. The relatively high concentration epimerized EGCG in tea beverages is due to the thermal conversion $(63,64)$. Therefore, heat sterilization in the autoclave (typically temperature $121-134^{\circ} \mathrm{C}$, steam, under pressure $100 \mathrm{kPa}, 20 \mathrm{~min}$ ), dry heat sterilization (typically $2 \mathrm{~h}$ at 160 or $190^{\circ} \mathrm{C}$ for $6 \mathrm{~min}$ ) have been eliminated. Chemical sterilization due to the high reactivity of EGCG is not suitable either.

We conclude that EGCG sterilization should be done through the use of low temperature sterilization methods, more precisely by ionizing radiation or the filtration method in conjunction with freeze-drying. Both of these methods use a low temperature process to reduce microbial contamination to an acceptable level that is recommended for years by the American and European Pharmacopoeias (65-67). It is estimated that approximately $90 \%$ of medications can be sterilized in the solid phase with a standard dose of $25 \mathrm{kGy}$. However, there is a risk that ionizing radiation in the standard sterilization dose may adversely affect the structure of EGCG. Therefore, we began to irradiate EGCG with a dose of $25 \mathrm{kGy}$, while increasing it to $200 \mathrm{kGy}$ to capture all changes occurring under the highenergy electron beam, and then subjected to the analytical tests

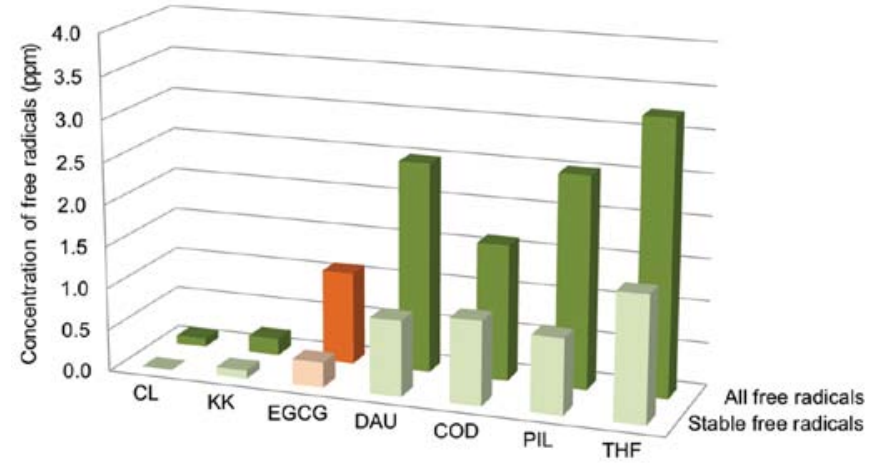

Figure 7. Concentration of free radicals after irradiation ( $25 \mathrm{kGy}$ dose) for epigallocatechin-3-gallate (EGCG) and other drugs (CL, clotrimazole; KK, ketoconazole; DAU, daunorubicin; COD, codeine phosphate; PIL, pilocarpine hydrochloride; THF, thiamphenicol) (57-64).

(EGCG, EGCG irradiated and lyophilization) using a variety of analytical methods. These should clearly answer the question of whether EGCG can be sterilized by radiation or by filtration. The sterilization dose (25 kGy) caused only a $0.5-0.6 \%$ decline in the content of EGCG, and ensured the sterility of the sample, which was confirmed by microbiological methods.

Measurement of the melting point method can be used to rapidly monitor the changes taking place after radiation. Literature data indicate that radiation degradation products reduce the melting point of irradiated drugs, by a very small value of $<1^{\circ} \mathrm{C}$, as observed for the ketoconazole irradiated dose of $200 \mathrm{kGy}(68)$ or be a few ${ }^{\circ} \mathrm{C}$. For example, hydrocortisone following irradiation at a dose of $100 \mathrm{kGy}$ changed the melting point by $7^{\circ} \mathrm{C}$ (69). EGCG irradiated with different doses led to changes in the melting point between these values and did not answer conclusively what occurred following radiation sterilization. In the case that the filtration and lyophilization of EGCG melting point analysis was not conclusive, this is most likely due to the fact that amorphous EGCG degraded before melting.

UV spectra of EGCG solutions before and after sterilization by different methods showed some changes in the case of filtration, confirmed by FTIR spectra of EGCG where we observed some differences in the range of 3,600-3,200 $\mathrm{cm}^{-1}$. In addition, HPLC chromatograms of EGCG before and after sterilization processes by filtration showed small additional peeks around retention time of approximately $3 \mathrm{~min}$, but were not observed in EGCG sterilized by radiation. That can be a result of auto- 
oxidation or epimerization, which are the two major reactions responsible for the instability of EGCG in aqueous solution (30).

There are no pharmacopeia standards for the quantity of free radicals in irradiated drugs. We found that the concentration of free radicals in irradiated samples of EGCG was very similar to the values obtained for drugs from different chemical groups and therapeutic (70-74) with the same dose, source and conditions of irradiation (Fig. 7). There are, however, drugs that following irradiation, show much higher levels of free radicals such as epidoxorubicin (EPI), 4.7/18.0; doxorubicin (DOX), 26.4/60.0 ppm of stable/all free radicals after irradiation. Nevertheless, there was no association between the concentration of free radicals and the degree of distribution relationship and all 3 tested antibiotics (DAU, DOX and EPI). It has been proven that the high content of free radicals in the sterilized subjected EPI and DOX causes the beneficial effecthigher cytotoxic activity against cells of the lymphoblastic leukemia line CCRF-VCR1000 (74). This, similarly, can be beneficial for EGCG, as well.

In conclusion, the sterilization by radiation and filtration $(0.2 \mu \mathrm{m})$ followed by freeze-drying cause only $0.5-0.6 \%$ decline in the content of EGCG, and at the same time both methods ensure the sterility of the sample, which was confirmed the microbiological research. Therefore, we can conclude that both methods are suitable to produce a sterile form of EGCG. However, infrared and HPLC analysis show better stability of irradiated EGCG over the filtration and lyophilization method. The concentration of stable free radicals following irradiation sterilization was $0.35 \mathrm{ppm}$, which is similar to the other drugs sterilized by the same method. The concentration is low and it is unlikely that the resulting free radicals exert any damaging effects to EGCG. The treatment of cells by EGCG sterilized by either method did not alter cell growth pattern as compared to untreated EGCG. This indicates that small modifications of EGCG will unlikely have any biological effects. Therefore, we conclude that radiation is the preferred method of EGCG sterilization, which is to be used in the treatment of superficial bladder cancer.

\section{References}

1. Raman JD, Messer J, Sielatycki JA and Hollenbeak CS: Incidence and survival of patients with carcinoma of the ureter and renal pelvis in the USA, 1973-2005. BJU Int 107: 1059-1064, 2011.

2. Madeb R, Golijanin D, Knopf J and Messing EM: Current state of screening for bladder cancer. Expert Rev Anticancer Ther 7: 981-987, 2007

3. Shen Z, Shen T, Wientjes MG, O'Donnell MA and Au JL: Intravesical treatments of bladder cancer: review. Pharm Res 25: 1500-1510, 2008.

4. Pan CW, Shen ZJ and Ding GQ: The effect of intravesical instillation of antifibrinolytic agents on bacillus Calmette-Guerin treatment of superficial bladder cancer: a pilot study. J Urol 179: $1307-1311,2008$

5. Macleod LC, Ngo TC and Gonzalgo ML: Complications of intravesical bacillus calmette-guérin. Can Urol Assoc J 8: E540-544, 2014.

6. Huang X, Yu HS, Chen Z, Li JL, Hu ZM and Gao JM: A novel immunotherapy for superficial bladder cancer by the immobilization of streptavidin-tagged bioactive IL-2 on the biotinylated mucosal surface of the bladder wall. Chin J Cancer 29: 611-616, 2010.

7. Harding GE and Lawlor DK: Ruptured mycotic abdominal aortic aneurysm secondary to Mycobacterium bovis after intravesical treatment with bacillus Calmette-Guérin. J Vasc Surg 46: 131-134, 2007
8. Mack D, Höltl W, Bassi P, Brausi M, Ferrari P, de Balincourt C and Sylvester R; European Organization for Research and Treatment of Cancer Genitourinary Group: The ablative effect of quarter dose bacillus Calmette-Guerin on a papillary marker lesion of the bladder. J Urol 165: 401-403, 2001.

9. Böhle A and Bock PR: Intravesical bacille Calmette-Guérin versus mitomycin $C$ in superficial bladder cancer: formal meta-analysis of comparative studies on tumor progression. Urology 63: 682-686, 2004.

10. Huncharek M and Kupelnick B: Chemotherapeutic prophylaxis of superficial bladder tumors. Oncology (Williston Park) 15: $1106,2001$.

11. Jankun J, Keck RW and Selman SH: Epigallocatechin-3-gallate prevents tumor cell implantation/growth in an experimental rat bladder tumor model. Int J Oncol 44: 147-152, 2014.

12. Suzuki Y, Miyoshi N and Isemura M: Health-promoting effects of green tea. Proc Jpn Acad Ser B Phys Biol Sci 88: 88-101, 2012.

13. Saito ST, Gosmann G, Pungartnik C and Brendel M: Green tea extract-patents and diversity of uses. Recent Pat Food Nutr Agric 1: 203-215, 2009.

14. Cooper R, Morré DJ and Morré DM: Medicinal benefits of green tea: part I. Review of noncancer health benefits. J Altern Complement Med 11: 521-528, 2005.

15. Higdon JV and Frei B: Tea catechins and polyphenols: health effects, metabolism, and antioxidant functions. Crit Rev Food Sci Nutr 43: 89-143, 2003.

16. Brown MD: Green tea (Camellia sinensis) extract and its possible role in the prevention of cancer. Altern Med Rev 4:360-370, 1999.

17. Jung YD and Ellis LM: Inhibition of tumour invasion and angiogenesis by epigallocatechin gallate (EGCG), a major component of green tea. Int J Exp Pathol 82: 309-316, 2001.

18. Shirakami Y, Shimizu M and Moriwaki H: Cancer chemoprevention with green tea catechins: from bench to bed. Curr Drug Targets 13: 1842-1857, 2012.

19. Zhang L, Wei Y and Zhang J: Novel mechanisms of anticancer activities of green tea component epigallocatechin-3-gallate. Anticancer Agents Med Chem 14: 779-786, 2014.

20. Zhu K and Wang W: Green tea polyphenol EGCG suppresses osteosarcoma cell growth through upregulating miR-1. Tumour Biol 37: 4373-4382, 2016

21. Tran PL, Kim SA, Choi HS, Yoon JH and Ahn SG: Epigallocatechin-3-gallate suppresses the expression of HSP70 and HSP90 and exhibits anti-tumor activity in vitro and in vivo. BMC Cancer 10: 276, 2010.

22. Thangapazham RL, Singh AK, Sharma A, Warren J, Gaddipati JP and Maheshwari RK: Green tea polyphenols and its constituent epigallocatechin gallate inhibits proliferation of human breast cancer cells in vitro and in vivo. Cancer Lett 245: 232-241, 2007.

23. Ahn WS, Huh SW, Bae SM, Lee IP, Lee JM, Namkoong SE, Kim CK and Sin JI: A major constituent of green tea, EGCG, inhibits the growth of a human cervical cancer cell line, CaSki cells, through apoptosis, G(1) arrest, and regulation of gene expression. DNA Cell Biol 22: 217-224, 2003.

24. Tosetti F, Ferrari N, De Flora S and Albini A: 'Angioprevention': angiogenesis is a common and key target for cancer chemopreventive agents. FASEB J 16: 2-14, 2002.

25. Singh BN, Shankar S and Srivastava RK: Green tea catechin, epigallocatechin-3-gallate (EGCG): mechanisms, perspectives and clinical applications. Biochem Pharmacol 82: 1807-1821, 2011.

26. Garbisa S, Sartor L, Biggin S, Salvato B, Benelli R and Albini A: Tumor gelatinases and invasion inhibited by the green tea flavanol epigallocatechin-3-gallate. Cancer 91: 822-832, 2001.

27. Kobalka AJ, Keck RW and Jankun J: Synergistic anticancer activity of biologicals from green and black tea on DU 145 human prostate cancer cells. Cent Eur J Immunol 40: 1-4, 2015.

28. Roomi MW, Ivanov V, Kalinovsky T, Niedzwiecki A and Rath M: Inhibition of cell invasion and MMP production by a nutrient mixture in malignant liposarcoma cell line SW-872. Med Oncol 24: 394-401, 2007.

29. Swiercz R, Skrzypczak-Jankun E, Merrell MM, Selman SH and Jankun J: Angiostatic activity of synthetic inhibitors of urokinase type plasminogen activator. Oncol Rep 6: 523-526, 1999.

30. Hou Z, Sang S, You H, Lee MJ, Hong J, Chin KV and Yang CS: Mechanism of action of (-)-epigallocatechin-3-gallate: auto-oxidation-dependent inactivation of epidermal growth factor receptor and direct effects on growth inhibition in human esophageal cancer KYSE 150 cells. Cancer Res 65: 8049-8056, 2005.

31. Bae MJ, Ishii T, Minoda K, Kawada Y, Ichikawa T, Mori T, Kamihira $M$ and Nakayama T: Albumin stabilizes (-)-epigallocatechin gallate in human serum: binding capacity and antioxidant property. Mol Nutr Food Res 53: 709-715, 2009. 
32. Zinellu A, Sotgia S, Scanu B, Forteschi M, Giordo R, Cossu A, Posadino AM, Carru C and Pintus G: Human serum albumin increases the stability of green tea catechins in aqueous physiological conditions. PLoS One 10: e0134690, 2015.

33. Dryden GW, Lam A, Beatty K, Qazzaz HH and McClain CJ: A pilot study to evaluate the safety and efficacy of an oral dose of (-)-epigallocatechin-3-gallate-rich polyphenon $\mathrm{E}$ in patients with mild to moderate ulcerative colitis. Inflamm Bowel Dis 19: 1904-1912, 2013.

34. Lambert JD, Lee MJ, Lu H, Meng X, Hong JJ, Seril DN, Sturgill MG and Yang CS: Epigallocatechin-3-gallate is absorbed but extensively glucuronidated following oral administration to mice. J Nutr 133: 4172-4177, 2003.

35. Scalia S, Marchetti N and Bianchi A: Comparative evaluation of different co-antioxidants on the photochemical- and functionalstability of epigallocatechin-3-gallate in topical creams exposed to simulated sunlight. Molecules 18: 574-587, 2013.

36. Bianchi A, Marchetti N and Scalia S: Photodegradation of (-)-epigallocatechin-3-gallate in topical cream formulations and its photostabilization. J Pharm Biomed Anal 56: 692-697, 2011.

37. Colomer R, Sarrats A, Lupu R and Puig T: Natural polyphenols and their synthetic analogs as emerging anticancer agents. Curr Drug Targets 18: 147-159, 2017.

38. Joe AK, Schnoll-Sussman F, Bresalier RS, Abrams JA, Hibshoosh H, Cheung K, Friedman RA, Yang CS, Milne GL, Liu DD, et al: Phase Ib randomized, double-blinded, placebo-controlled, dose escalation study of polyphenon $\mathrm{E}$ in patients with Barrett's esophagus. Cancer Prev Res (Phila) 8: $1131-1137,2015$.

39. Kato MT, Leite AL, Hannas AR and Buzalaf MA: Gels containing MMP inhibitors prevent dental erosion in situ. J Dent Res 89: 468-472, 2010.

40. Stockfleth E and Meyer T: The use of sinecatechins (polyphenon E) ointment for treatment of external genital warts. Expert Opin Biol Ther 12: 783-793, 2012.

41. Gross G, Meyer KG, Pres H, Thielert C, Tawfik $H$ and Mescheder A: A randomized, double-blind, four-arm parallel-group, placebo-controlled phase II/III study to investigate the clinical efficacy of two galenic formulations of polyphenon $\mathrm{E}$ in the treatment of external genital warts. J Eur Acad Dermato Venereol 21: 1404-1412, 2007.

42. Kemberling JK, Hampton JA, Keck RW, Gomez MA and Selman SH: Inhibition of bladder tumor growth by the green tea derivative epigallocatechin-3-gallate. J Urol 170: 773-776, 2003.

43. Selman SH and Keck RW: A comparative study of the inhibiting effects of mitomycin $C$ and polyphenolic catechins on tumor cell implantation/growth in a rat bladder tumor model. J Urol 186: 702-706, 2011.

44. Mai VC, Bednarski W, Borowiak-Sobkowiak B, Wilkaniec B, Samardakiewicz $S$ and Morkunas I: Oxidative stress in pea seedling leaves in response to Acyrthosiphon pisum infestation. Phytochemistry 93: 49-62, 2013.

45. Mossanen M and Gore JL: The burden of bladder cancer care: direct and indirect costs. Curr Opin Urol 24: 487-491, 2014.

46. Srinivasan H, Allory Y, Sill M, Vordos D, Alhamdani MS, Radvanyi F, Hoheisel JD and Schröder C: Prediction of recurrence of non muscle-invasive bladder cancer by means of a protein signature identified by antibody microarray analyses. Proteomics 14: 1333-1342, 2014.

47. Lohi J, Kyyrönen P, Kauppinen T, Kujala V and Pukkala E: Occupational exposure to solvents and gasoline and risk of cancers in the urinary tract among Finnish workers. Am J Ind Med 51: 668-672, 2008

48. Siemiatycki J, Dewar R, Krewski D, Désy M, Richardson L and Franco E: Are the apparent effects of cigarette smoking on lung and bladder cancers due to uncontrolled confounding by occupational exposures? Epidemiology 5: 57-65, 1994.

49. Isharwal S and Konety B: Non-muscle invasive bladder cancer risk stratification. Indian J Urol 31: 289-296, 2015.

50. Mansoor M, Ali S, Fasihuddin Q and Baloch MU: Superficial bladder tumours: recurrence and progression. J Coll Physicians Surg Pak 21: 157-160, 2011.

51. Palou-Redorta J, Solsona E, Angulo J, Fernández JM, Madero R, Unda M, Martínez-Piñeiro JA, Portillo J, Chantada V and Moyano JL: Retrospective study of various conservative treatment options with bacille Calmette-Guérin in bladder urothelial carcinoma T1G3: maintenance therapy. Actas Urol Esp 40: 370-377, 2016.
52. Iida K, Naiki T, Kawai N, Etani T, Ando R, Ikegami Y, Okamura T, Kubota H, Okada A, Kohri K, et al: Bacillus Calmette-Guerin therapy after the second transurethral resection significantly decreases recurrence in patients with new onset high-grade T1 bladder cancer. BMC Urol 16: 8, 2016.

53. Porten SP, Leapman MS and Greene KL: Intravesical chemotherapy in non-muscle-invasive bladder cancer. Indian J Urol 31: 297-303, 2015.

54. deKernion JB, Huang MY, Lindner A, Smith RB and Kaufman JJ: The management of superficial bladder tumors and carcinoma in situ with intravesical bacillus Calmette-Guerin. J Urol 133: 598-601, 1985.

55. Serretta V: Management, and prevention, of intravesical therapy complications. Urologia 76: 19-28, 2009 (In Italian).

56. Chopin DK: Intravesical instillation in the treatment of superficial tumors of the bladder. Prog Urol 8: 268-273, 1998 (In French).

57. Llopis M, Moreno J, Botella R and Algado M: Incrusted cystitis after intravesical mitomycin C treatment. Acta Urol Belg 61: 21-23, 1993.

58. Punga-Maole ML, Hubert $\mathrm{J}$ and Mangin P: Bladder retraction, a complication of chemoprophylaxis of superficial bladder cancer using intravesical mitomycin C. Prog Urol 5: 580-585, 1995 (In French)

59. Mereles D and Hunstein W: Epigallocatechin-3-gallate (EGCG) for clinical trials: more pitfalls than promises? Int J Mol Sci 12: 5592-5603, 2011

60. Jankun J, Kondray V and Skrzypczak-Jankun E: Analysis of the inhibition of PAI-1 by metal theaflavin complexes and their degradation products. Int J Mol Med 31: 1153-1158, 2013.

61. Zhao H, Zhu W, Xie P, Li H, Zhang X, Sun X, Yu J and Xing L: A phase I study of concurrent chemotherapy and thoracic radiotherapy with oral epigallocatechin-3-gallate protection in patients with locally advanced stage III non-small-cell lung cancer. Radiother Oncol 110: 132-136, 2014.

62. Shanafelt TD, Call TG, Zent CS, Leis JF, LaPlant B, Bowen DA, Roos M, Laumann K, Ghosh AK, Lesnick C, et al: Phase 2 trial of daily, oral polyphenon $\mathrm{E}$ in patients with asymptomatic, Rai stage 0 to II chronic lymphocytic leukemia. Cancer 119: 363-370, 2013.

63. Chen Z, Zhu QY, Tsang D and Huang Y: Degradation of green tea catechins in tea drinks. J Agric Food Chem 49: 477-482, 2001.

64. Lee SM, Kim CW, Kim JK, Shin HJ and Baik JH: GCG-rich tea catechins are effective in lowering cholesterol and triglyceride concentrations in hyperlipidemic rats. Lipids 43: 419-429, 2008.

65. Council of Europe: European Pharmacopoeia. 8th edition. Strasbourg, France, 2014.

66. The United States Pharmacopeial Convention (USP): The United States Pharmacopoeia 39 - National Formulary 34 (USP 39-NF 34). USP, Rockville, MD, 2015.

67. Marciniec B and Dettlaff K: Radiation sterilization of drugs. In: Trends in Radiation Sterilizationof Health Care Products. IAEA, Vienna, Austria, pp187-230, 2008.

68. Marciniec B, Kozak M, Wachowski L and Ogrodowczyk M: Evaluation of radiostability of some steroid derivatives. J Therm Anal Calorim 73: 473-485, 2003.

69. Marciniec B, Kozak M and Dettlaff K: Thermal analysis in evaluation of the radiochemical stability of some fungicidal drugs. J Therm Anal Calorim 77: 305-317, 2004.

70. Marciniec B, Dettlaff K, Danikiewicz W, Spólnik G, Jaroszkiewicz E and Naskrent M: Radiostability of ketoconazole in the solid state. Curr Pharm Anal 9: 102-113, 2013.

71. Marciniec B, Dettlaff K and Naskrent M: Influence of ionising irradiation on clotrimazole in the solid state. J Pharm Biomed Anal 50: 675-678, 2009.

72. Marciniec B, Kozak M, Naskrent M, Hofman M, Dettlaff K and Stawny M: DSC and EPR analysis of some radiation sterilized alkaloids. J Therm Anal 102: 261-267, 2010.

73. Marciniec B, Stawny M,Kozak M and Naskrent M: The influence of radiation sterilization on thiamphenicol. Spectrochim Acta A Mol Biomol Spectrosc 69: 865-870, 2008.

74. Paszel-Jaworska A, Totoń E, Dettlaff K, Kaczmarek A, Bednarski W, Oszczapowicz I, Jelińska A and Rybczyńska M: Increased proapoptotic activity of electron beam irradiated doxorubicin and epirubicin in multidrug-resistant human leukemic cells. Chem Biol Interact 258: 69-78, 2016. 